\title{
CLUSTER DEVELOPMENT IN THE SA TOOLING INDUSTRY
}

\author{
K. von Leipzig ${ }^{*}$ \& D. Dimitrov ${ }^{2}$ \\ Department of Industrial Engineering \\ Stellenbosch University, South Africa \\ ${ }^{1} \mathrm{kvl} @$ sun.ac.za, 2 Dimitrov@sun.ac.za
}

\begin{abstract}
This paper explores the concept of clustering in general, analysing research and experiences in different countries and regions, and summarising factors leading to success or contributing to failure of specific cluster initiatives. Based on this, requirements for the establishment of clusters are summarised. Next, initiatives especially in the South African tool and die making (TDM) industry are considered. Through a benchmarking approach, the strengths and weaknesses of individual local tool rooms are analysed, and conclusions are drawn particularly about South African characteristics of the industry. From these results, and from structured interviews with individual tool room owners, difficulties in the establishment of a South African tooling cluster are explored, and specific areas of concern are pointed out.
\end{abstract}

\section{OPSOMMING}

Hierdie artikel kyk in die algemeen na die beginsel van groeperingsnetwerk, gebaseer op navorsing en ondervinding van die beginsel in verskillende lande en streke, en 'n analise van die faktore wat kan lei tot sukses of wat moontlik bydra tot falings met spesifieke groeperingsnetwerk inisiatiewe. Gebaseer daarop word die voorwaardes vir die daarstelling van so 'n groeperingsnetwerk bespreek. Van die inisiatiewe in Suid-Afrika, spesifiek in die gereedskap en passtuk vervaardigingsindustrie, word bespreek. Deur 'n ondersoek word sterk en swak punte van individuele gereedskapmakers analiseer, en afleidings word gemaak oor die stand van die industrie in Suid-Afrika oor die algemeen. Met die afleiding en deur middel van gestruktureerde onderhoude met individuele gereedskap werkswinkeleienaars, word probleme in die totstandbrenging van 'n Suid-Afrikaanse gereedskap groepering ondersoek, en spesifieke areas wat verdere analise nodig het, uitgelig.

* Corresponding author 
"The classical business model of the tooling industry is dead," says ISTMA's European president Menezes about the future of the industry. "In Eastern Europe and China tools and components are 30\% cheaper than in Germany - with the same quality and speed," agrees Visteon's European Director Greiss, as quoted by Frick [1].

Globally, it is accepted that the tool, die and mould (TDM) industry is a key contributor to the industrial value-adding chain. Being the link between product development and production, it is responsible for ascertaining whether innovative and new product designs can be brought to the market within acceptable parameters such as price, quality, etc. The percentage of tooling costs within the new product development process is very high: for an average car-series, approximately 15 per cent of the total production line investment is made in tooling, with up to 30 per cent of the production cost being defined through tool selection [2]. The availability of effective TDM will make the difference between economically viable products and failures.

The TDM tasks are extremely complex: tools are unique products, made to the individual requirements of specific customers, and a high degree of flexibility, skill, and knowledge are required. Designing and making tools is thus very labour-intensive, and, because there are many non-quantifiable variables, a high degree of experience in an individual toolmaker is vital. However, tooling not only makes significant contributions to product innovation and manufacturing costs, but also impacts on time. As an example, the manufacturing of tools required for the bodyworks of a car accounts for almost half the total product development time [1].

The total value of the TDM industry worldwide increased from US\$22 billion in 2004 to an estimated US\$90 billion in 2012 [2], with Germany, the USA, and China leading in terms of turnover. Most TDMs around the world are small to medium enterprises (SMEs), with price as the leading factor of competition and delivery time, and product quality being regarded as the next most important evaluation criterion [3].

In South Africa too, the tool-, die- and mould-making (TDM) industry faces tremendous challenges from globalisation. In general, the industry has fewer innovative and technologically-advanced designs compared with (for example) German designs, and also faces increasing competition from especially low cost countries such as China and India. Because of this, and the fact that 85 per cent of required tools are imported [2], local tool manufacturers need to look at ways to improve their competitiveness.

Clustering of activities has been proven to be very effective, and can enable rapid growth and economic success for the firms involved in such a cluster. Examples such as the 'Third Italy' in a developed country, Kenya's Agricultural Products Cluster in a developing country, and the automotive cluster of Thailand (which emerged in the 1990s as an example of a complex cluster spanning several related industries) all show that a properly developed cluster can be responsible for a huge increase in competitiveness [4]. This has led to many countries and regions deploying the concept, as illustrated in Figure 1, showing that there were more than 1,400 cluster initiatives around the world in 2006. Indicated in Figure 1 are the number of initiatives in the various regions, showing that South Africa, with 25 such activities, has also embraced the concept.

The main objective of this paper is thus to analyse existing cluster models and to identify adaptations required to develop a framework for the establishment of clusters in the South African environment. Important differences between SMMEs in the so-called 'first world' countries and those in developing economies in general, and the responsibilities of all role players within the broader economic framework of South Africa specifically, have been addressed. 


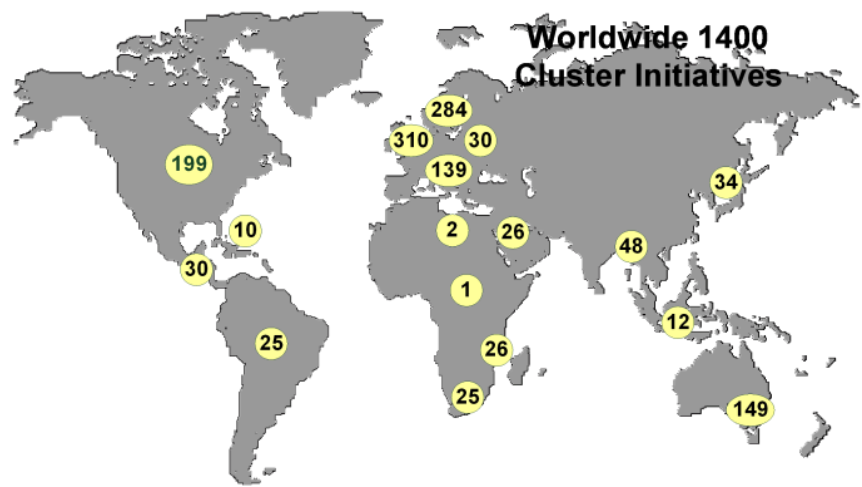

Figure 1: Survey of current clusters in the world (adapted from [5])

\section{THE TOOLING INDUSTRY}

Global economies demand the manufacture of a diverse range of products, and tool making is at the heart of component manufacturing.

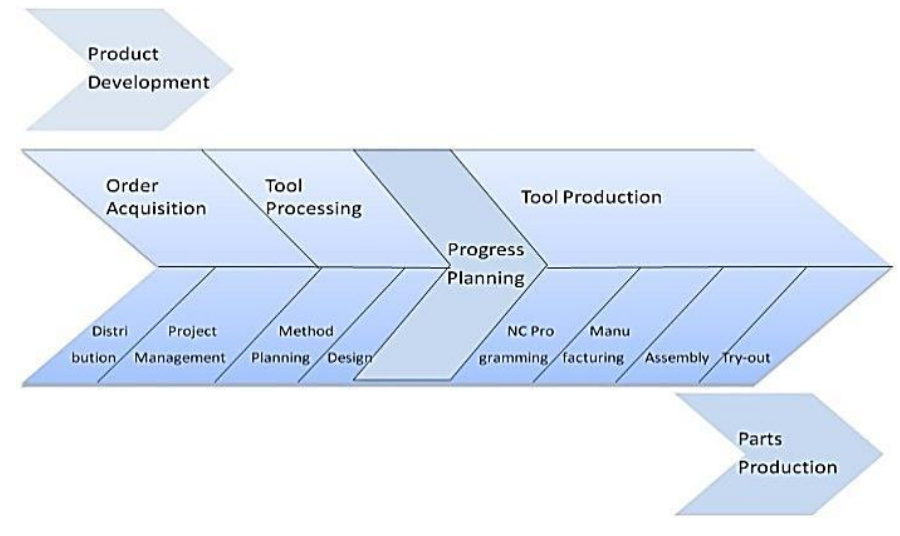

Figure 2: Value chain of the TDM industry (adapted from [1])

The value chain of the TDM industry consists in general of order acquisition, tool processing, progress planning, and tool production as illustrated in Figure 2. This shows a complex process, from the original product as designed by the product manufacturer, through tool design, to the ultimate manufacture of the end product. Bilsing \& Klocke [6] agree that it is an essential element of the component manufacturing value chain. According to the counterpart group [3], when material purchases, conversion rates, turnover levels, and supply prices to the industry are taken into consideration, the valueadded factor for tooling is estimated at $1: 19$. This equates to a 19-fold increase in the economic value of the cost input to produce a tool, die, or mould. Also of interest is the fact that between 70 per cent andto 90 per cent of all tooling manufacturers worldwide are supplying to the automotive industry or to their immediate or tier 1 suppliers [7].

\subsection{Tooling in South Africa}

The South African tooling industry is currently working significantly below domestic demand, while battling with aging and low-tech capital layout equipment [8]. In order to assess the current status of the SA tooling industry, including its strengths and weaknesses, and within the context of the growing demands placed on it, a benchmarking process is actively pursued. Here core competencies and key indicators of specific tool rooms in SA were analysed and compared with international competitors. Malherbe [8] and Kuhlmann [9] analysed the initial results, based on the benchmarking of 40 individual tool rooms, and 
both come to the conclusion that, as far as the tool manufacture value chain is concerned, SA tooling companies exhibit:

- $\quad$ Average cost for concept and design;

- Low levels of on-line NC-programming;

- Very high efforts for metal-cutting;

- Low cost for finishing and final assembly; and

- $\quad$ Little or no support for first-off tool.

These results clearly indicate that the early and late phases of value creation are neglected. Furthermore, the SA tooling industry is characterised by:

- (Relatively) low labour costs;

- $\quad$ (Relatively) high interest rates;

- Relatively low academic qualification of management and design staff; and

- Difficulties in data collection and manipulation.

According to Malherbe [8], as far as long-term competitiveness and sustainability are concerned, the initial results paint a bleak picture. This is indicated in Figure 3, which shows different scenarios of turnover against turnover profitability. For long-term sustainability, Scenario 4 would be ideal, as both a high turnover and high turnover profitability would allow the company to re-invest at least part of its profits back into the enterprise through, for example, purchasing new technology or spend on R\&D. However, sole-owned small tool rooms in South Africa usually find themselves in Scenario 3. Profitability is maximised, usually at the expense of continuous improvement. This allows the owner to maximise his/her return in the short term. This scenario will eventually lower the comparative competitiveness of a tool room, and can be detrimental to the sustainability of such an enterprise.

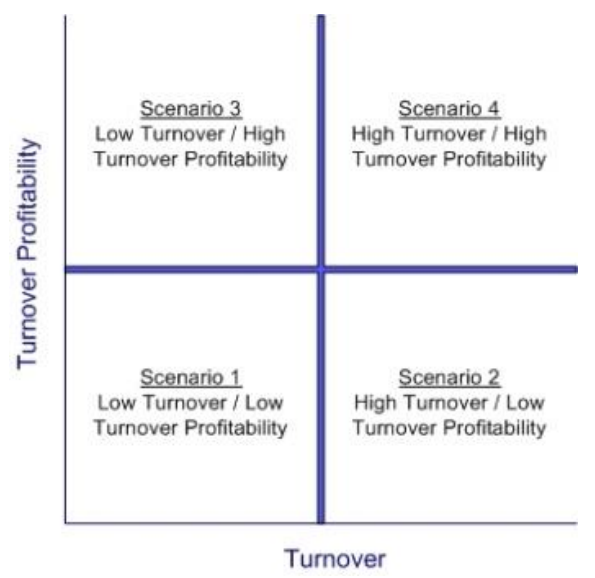

Figure 3: Significance of performance in turnover and turnover profitability [8]

Because of the significance of the TDM industry within the SA manufacturing sector, global competitiveness and the continuity of workload have to be increased if it is to survive. To facilitate this, strategic intervention by government is essential. A coherent action plan for improvement intervention should be coordinated amongst the major TDM consumers, TDM manufacturers, and suppliers to the TDM industry. A set of good tool-making practices needs to be developed. Tool rooms that adhere to these practices should be identified and marketed to major tooling consumers (automotive and packaging). These major consumers should benefit through import credits (as in the South African Motor Industry Development Programme (MIDP)) or through any other economic activity when they purchase products from the identified toolmakers. 


\subsection{Collaboration}

Collaboration among tool rooms is necessary to uplift competitiveness of the industry. Four main reasons for clustering can be identified:

1. Small enterprises do not have the capacity to invest in the required technologies and skills development. Clustering offers the opportunity to share technologies and training programmes. Benefits from the establishment of independent tooling clusters with tool rooms as members will increase the efficient use of resources throughout the industry.

2. The lack of capacity in a single tool room to conduct large commissions forces clients to order from large international tooling organisations. Clustering to share capacity will increase the benefit to large tooling consumers, given local content requirements, especially for the automotive and packaging industries.

3. Tool rooms can gain knowledge and experience by focusing on specific processes in cluster formations. Specialisation, in which one commission is sectioned according to the capabilities of various tooling organisations, will increase efficiency.

4. Combined bids in joint ventures can be proposed, making it possible to undertake larger projects that would have gone elsewhere otherwise.

\section{CLUSTERING}

As early as 1991, Malone [10] recognised that "the revolution under way today will be driven not by changes in production but by changes in coordination".

SMEs are recognised as playing a vital role in almost every country in creating economic growth and employment [11]. In South Africa, the importance of SMEs cannot be overestimated. "South Africa's 2-million small businesses represent $98 \%$ of the country's total number of firms, employ $55 \%$ of the labour force and contribute $42 \%$ of the country's wage bill, yet $87 \%$ of these enterprises are survivalist and operate outside the formal economy" [12].

The statistics below present the findings of telephonic interviews with more than 5,000 business and financial decision-makers in the small, medium and micro enterprise (SMME) sector across vertical markets of South Africa. This survey aimed to identify the environmental and infrastructural challenges facing SMMEs, and to determine how SMMEs act to remain competitive (compiled from SME survey [13]). As shown in Figure 4, nearly two-thirds of all respondents employ not more than 20 workers, while every fourth company employs a staff of only five or fewer persons. Nevertheless, as shown in Figure 5, four out of five companies achieve positive cash flows.

Sum et al. [11] recognise two vital parameters that create successful SMEs: operations play a pivotal role in identifying corporate strategy (a point supported by other authors such as Boyer and Lewis [14], Bozarth and McDermot [15], and Hayes et al. [16]), and that longaccepted corporate boundaries are giving way to new forms of organisations, or virtual enterprises.

As for new structures, little research has been published on the organisational and economic infrastructure within which SMEs operate [17]. Yet the cost structures within these new corporate networks are often different from those of the existing or traditional companies, necessitating a fresh look at strategies and at costing or measuring frameworks and models for managing operations [16].

According to Hayes et al. [16], within these forms, clustering is seen as a possible driver or structure that allows the measuring of frameworks and models for managing operations. The global interest in this concept is shown in Figure 6 which, like Figure 1, gives an indication of clustering activities worldwide. 


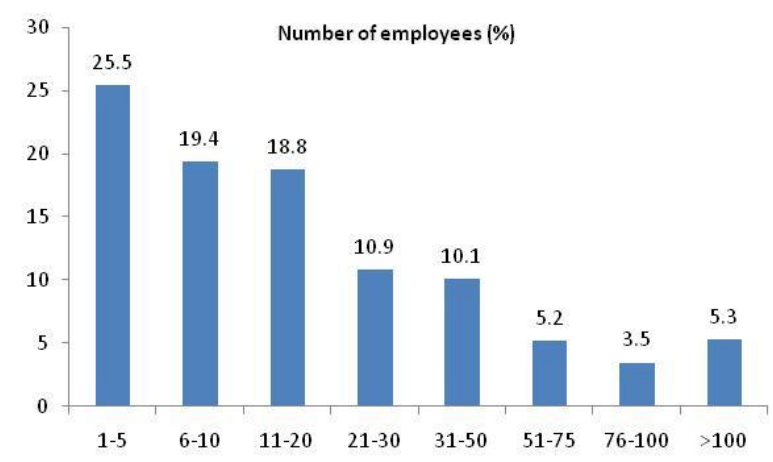

Figure 4: Number of people employed by SMEs (based on [13])

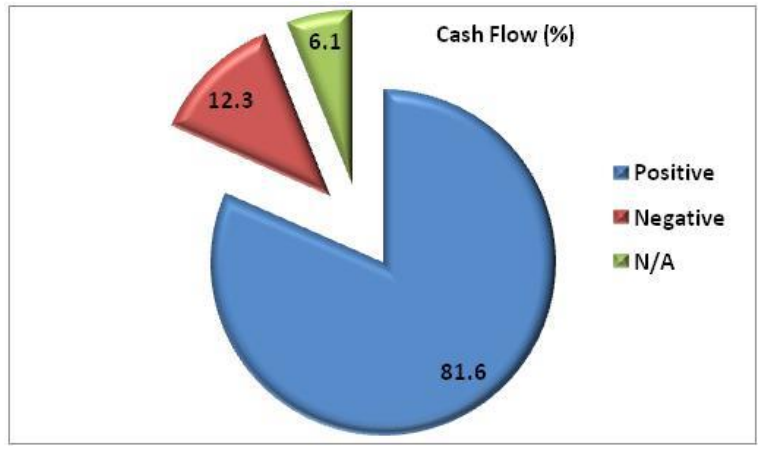

Figure 5: Cash flow within SMEs (based on [13]) (see online version for colour images)

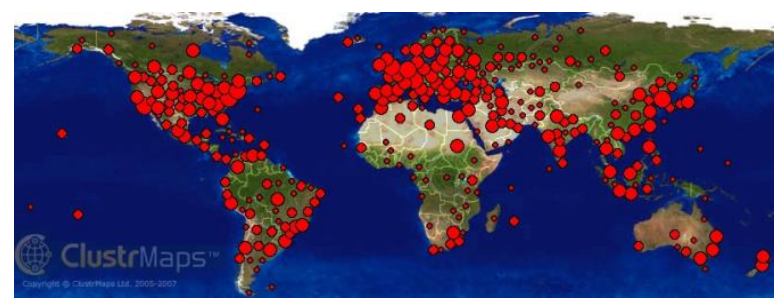

Figure 6: Cluster map (see online version for colour images) http://www2.clustrmaps.com/counter/maps.php?url=http://clustrmaps.com

\subsection{Cluster objectives}

Sölvell [18] defined clustering activities as follows: "Cluster initiatives are organized efforts to increase the growth and competitiveness of clusters within a region, involving cluster firms, government and/or the research community". According to Boltz et al. [4], six main objectives of cluster initiatives (Cls) can be identified. These are shown in Figure 7, and are briefly explained below:

- Employees: A necessary objective, especially for cluster expansion and maintenance, is to ensure the attractiveness of the region or cluster environment so as to attract the proper skills, and to train and educate the workforce further through vocational training, technical training, and management education.

- Cluster expansion: Incubators are vital elements to combine the provision of physical facilities with assistance in setting up business plans and financial plans, and to help entrepreneurs get in touch with financiers and potential customers.

- Business development: It is vital to promote different operations within different companies of the cluster to achieve higher productivity and efficiency levels. 


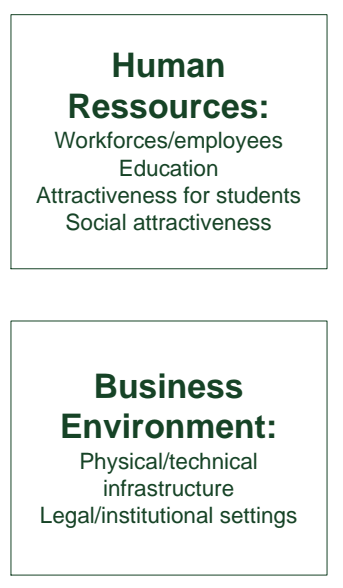

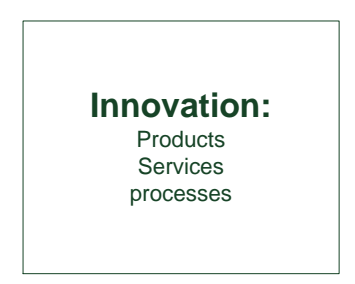

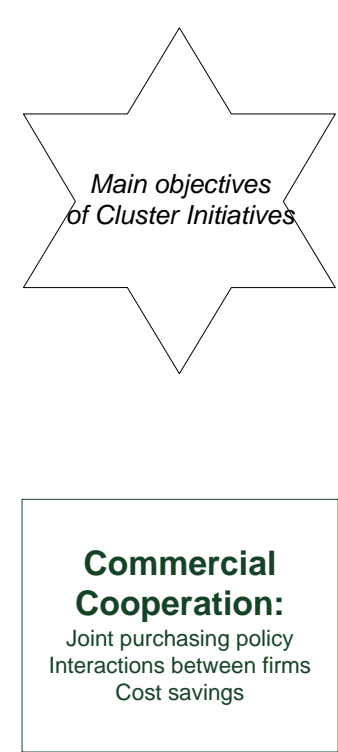

Figure 7: Main objectives of Cls [4]

- Commercial cooperation: Agglomeration of joint purchasing policies and general interactions between the different firms within the cluster focus on economies of scale and saving costs.

- Innovation: Development of quality through product, service, and process innovation is strived for through networking between the firms and cooperation with the research/ academic sectors in the region.

- Business environment: To improve the infrastructure outside the firms, government (mainly) is responsible for developing physical/technical infrastructure and aligning legal/institutional settings with the needed status to allow the cluster to evolve in a competitive way.

\subsection{Difficulties experienced}

Schuh et al [19] state that there are a number of difficulties that need to be addressed and overcome when developing a cluster. These difficulties are shown in Figure 8.

- Ambiguous and incomplete definitions of the purpose and goals of each the participants at the start of a network. It is thus vital that time is spent to define clearly the purpose of the cluster and the specific aims of each participant.

- Adaption. As with any process change there will be resistance. This is even more complicated where different companies need to work together, normally with different management structures and hierarchies.

- Clashing of systems. Individual partners often use their own routines and, as no proper trust basis has been developed yet, it will be almost impossible to combine these systems into one working system for the new structure: at best partners will be disappointed, and at worst will blame each other. 


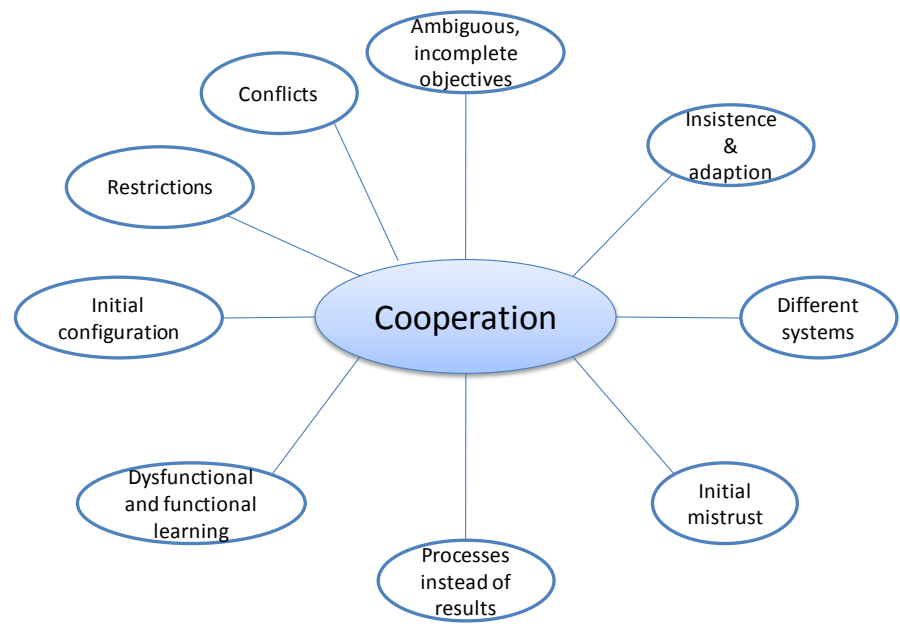

Figure 8: Difficulties experienced in cooperation (adapted from [19])

- Initial suspicions. Whenever one works with new partners there will be mistrust, so that small differences will often be blown out of proportion and lead to actions not conducive to cooperation.

- Process focus instead of result orientation. Cooperation cannot normally be based on the expected results, as these cannot be specified at the start. It has to be based on the processes within the cluster. If this concern is not addressed specifically and the cooperation is planned on paper only, the expected results will not materialise.

- Dysfunctional and functional learning. Learning will always be taking place: new processes will be analysed and accepted or refined. Learning will only become dysfunctional if there is a continuous negative experience with a partner, eventually leading to a complete breakdown of trust. It is thus vital that any learning experience be discussed openly and that changes be specifically accepted.

- The importance of the initial situation. In many cases in the literature, the importance of the initial position is overemphasised. It is accepted by some that the proper selection of partners to create a good fit and clear strategies will automatically result in successful cooperation. However, it is possible that cooperation can completely change in character over a very short period of time. As stated by Schuh et al [19]: “A co-operation agreement is a constantly evolving bargaining among the partners and a long-term view is necessary for cooperation to emerge and survive in a 'win-win' situation"

- $\quad$ Restrictions. Even in single enterprises there are restrictions “....for wide classes of organizations there are very strong inertial pressures on structures arising from both internal arrangements (for example internal politics) and from the environment (for example, public legitimation of organizational activity). To claim otherwise is to ignore the most obvious feature of organizational life" [19].

- Conflicts. Cooperationfaces a multitude of potential conflicts, beginning with people not seeing the necessity for cooperation; power and/or goal conflicts; personal conflicts; and many more. These possibilities have to be addressed and solved as early as possible.

\subsection{Cooperation typology}

Given the above difficulties, a specific cooperation typology is required. The learning curve of companies looking at cooperation is long and complex, and there is no 'one size fits all' approach. But the following three steps have been developed by Harbison/Pekar (as shown in Figure 9) and described by Schuh [19]. They range from an 'ad hoc' approach, where cooperation exists but is dependent on the activities of some engaged and dedicated individuals; through the 'lone ranger' approach, where some best practices do exist; to ultimately institutionalising these best practices. 


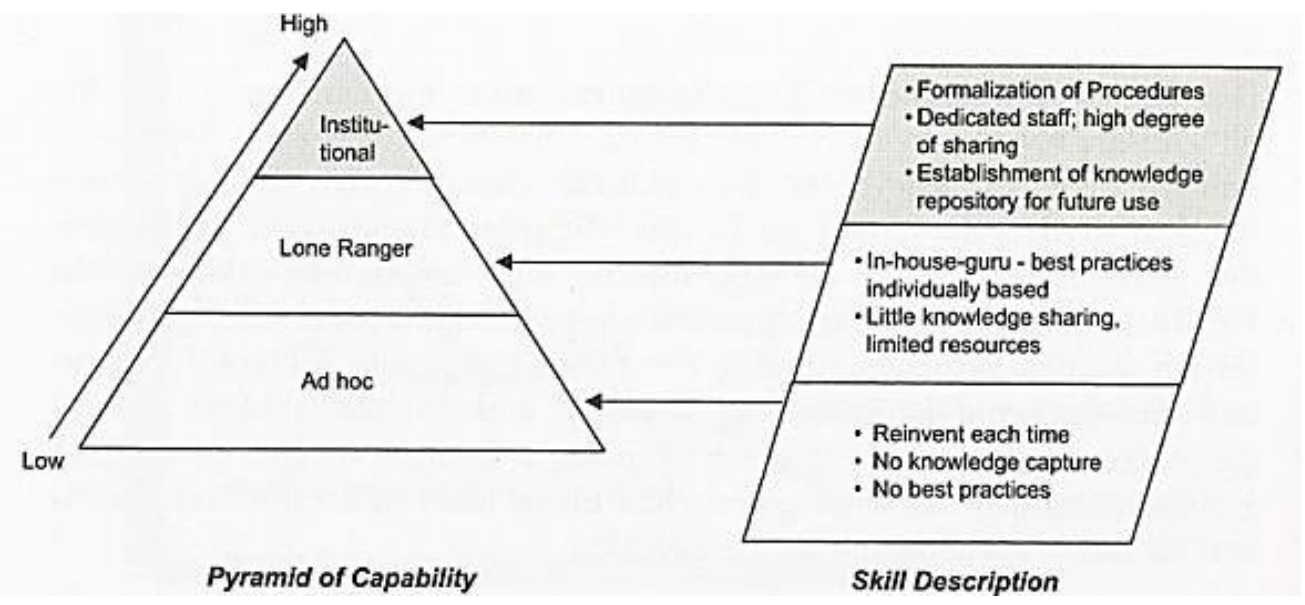

Figure 9: On the way towards institutionalised cooperation management (adapted from [19])

Dyer et al. [20] describe the core purpose of institutionalised cooperation management as:

- Knowledge management and learning;

- $\quad$ External visibility and support;

- Internal coordination and legitimacy; and

- $\quad$ Alliance assessment and intervention to fix problems.

In their study they found that companies that have formal structures in place and manage their cooperation professionally have higher success rates in their alliances.

\subsection{Requirements for a successful cluster}

Given the difficulties and requirements discussed above, are there basic principles on a lower level that increase the chances for success? Although it was stated earlier that there is no 'one size fits all' recipe that would be valid for all networks, as long ago as 1998 Millarg [21] identified autonomy and independence as an important requirement for any potential network. Partners should not be dependent on the cluster for economic and/or financial survival. Furthermore, partners should have minimum competencies on both a technical and a cooperation level.

- Technical competencies: These have to be brought into the network, and are normally based on core competencies on a technical level that have to complement those of other partners; and

- Co-operation competency: As discussed earlier, co-operation has to be managed professionally in order to increase the chances of success. The network or cluster should only open up additional possibilities, and as such the individual companies have to accept the need for cooperation.

According to Schuh [19], there are different kinds of 'networkers', as illustrated in Figure 10. These range from 'leeches' who do not really contribute either technically or through their cooperation and people skills, to technical specialists and 'sweepers' who contribute through their cooperation competence rather than their technical capabilities. Ideally, partners would have high technical competence as well as high cooperation competencies and formalised systems and structures. It is especially the latter requirement that is important in the South African context. 


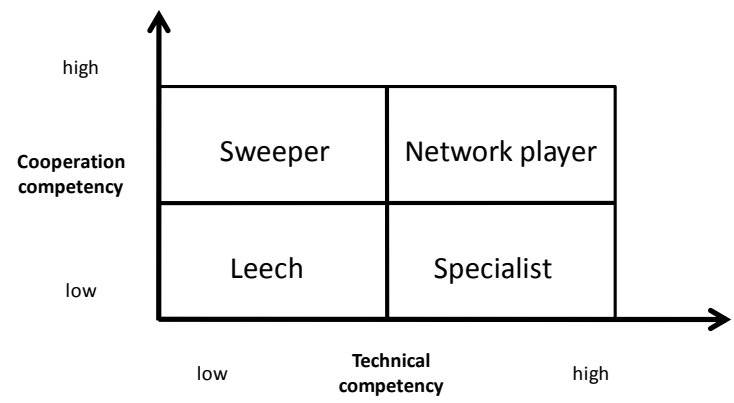

Figure 10: Typology of network players (adapted from [19])

\subsection{Specific requirements in developing economies}

The above concepts have been developed mainly in established economies. However, according to Rosenfeld [22], as far as developing economies are concerned, there are specific problem areas that need to be addressed too. These include generally weak infrastructure, lack of access to capital and technology, regional insularity and isolation, low educational levels resulting in a relatively low-skilled work force, and in general an absence of innovation, with antiquated industry structures that lead to social, technological, and economic exclusion. These exclusions involve isolated, underprivileged, and undereducated populations, poor access to sources of technology and benchmark companies, and weak links to benchmark regions and markets. These problems are summarised in Figure 11, and provide a guideline for additional considerations in developing a cluster framework in less-developed regions. Nevertheless, the basic requirements for cluster formation are still based on the same first-world principles of cooperation.

\subsection{Specific requirements for the TDM industry}

Studies looking specifically at the TDM industry have shown that there are a number of prerequisites for competitiveness. As a result of a survey of 180 German tooling companies and structured interviews with industry experts, Pittrich and Fecht (quoted by Frick [1]) identified 10 possible ways to improve the industry. These include: a complete understanding of their individual strengths and weaknesses; identification and quantification of these through benchmarking; grasping new markets; developing modular tool structures; being open or receptive to new ways and/or processes; developing their own personnel; making use of simulation; developing cost transparency; making use of low labour cost countries for non-critical parts; and, most importantly, participating in networks.

Fravel (quoted by Frick [1]) summarised the perspectives of the American Mould Builders Association (AMBA) as five strategies to improve TDM competitiveness. These are largely supported by the Michigan Manufacturing Technology Center (summarised by Cleveland [23]):

- Cost reduction through reduced overheads, lower salaries, or personnel reduction;

- Improved efficiencies, through the application of lean principles and automation;

- Diversification, through development of different markets and/or industries;

- Specialisation, by focusing on specific niches related to capacities; and

- Cooperation especially with international partners.

Eversheim et al. [24] identified the following factors as requirements for 'best-in-class' tool rooms:

- Strategy: Focusing on main customers and specific core competencies, integration into the value chain of the customers, a high involvement in the development of new tools; 


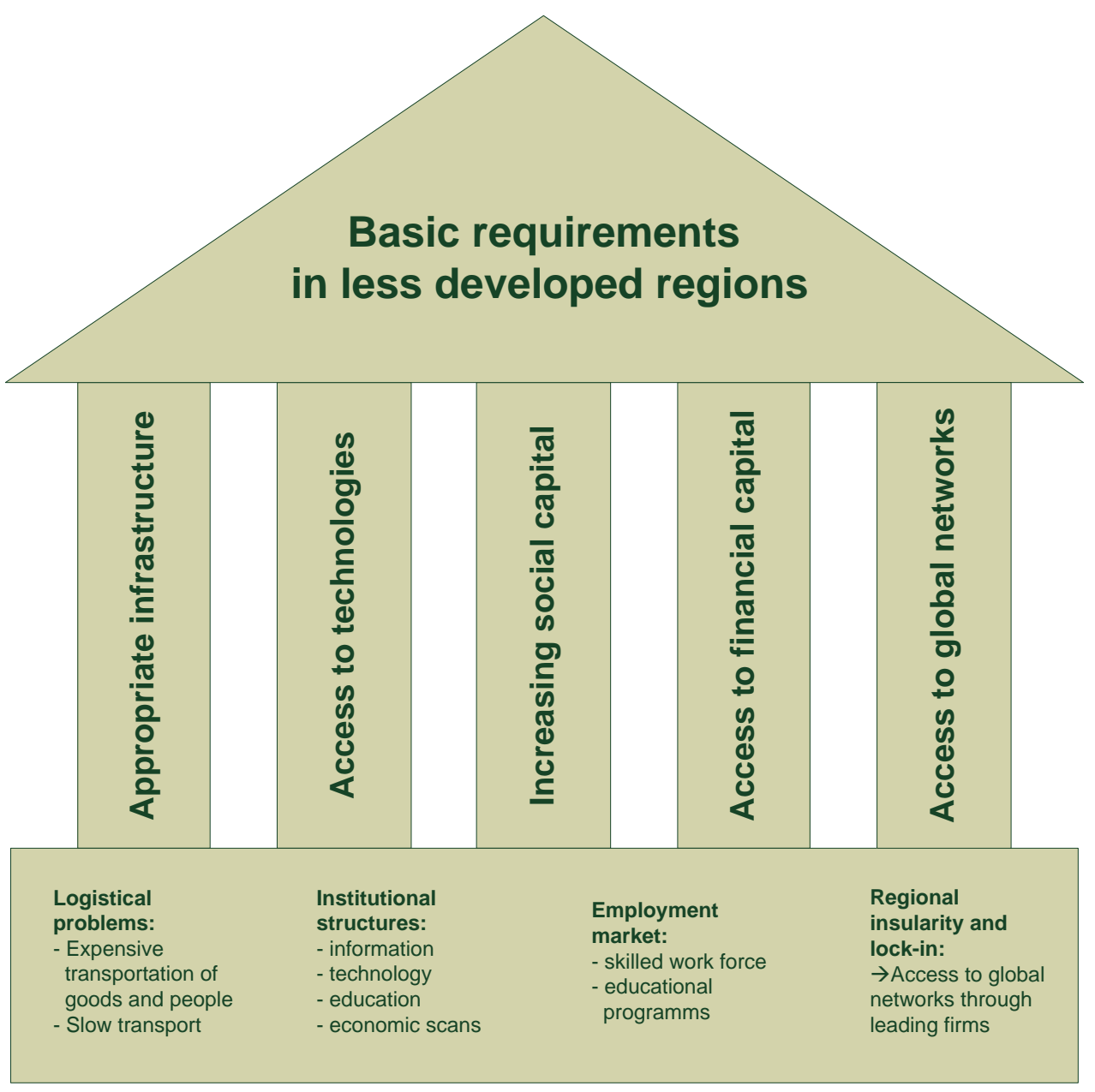

Figure 11: Basic requirements in less developed regions [22]

- Organisation: Being process-focused, being flexible, but having a high machine use, concentrating on core competencies;

- Technology: Concentrating on hard-to-accomplish designs, automating and investing in newest technologies;

- IT infrastructure: Having a 100 per cent CAD quota, a clear programming strategy, and transparent and visible systems planning and controlling software.

There is thus growing evidence that there are specific dynamics within the TDM industry. There is a trend away from small, craft-oriented, and loosely organised tool rooms towards bigger, technology-oriented, and focused companies that use an extended partner network to provide extended solutions to specific industries.

\section{ESTABLISHING A CLUSTER}

The quality of any cluster depends on the interaction between the partners. It is vital therefore that every member understands and executes their own role within that network.

\subsection{Cluster life cycle}

Schuh [19] states that, for a cluster to be successful, certain 'rules and regulations' have to be adhered to, and a specific infrastructure has to be developed. This is based on the life 
cycle of a network, starting with the marketing phase and ending with the eventual dissolution, as indicated in Figure 12.

The general responsibilities of each player need to be established. These range from the network coach who is responsible for the development, maintenance, and refinements of the network and its infrastructure, and who also manages conflict resolution, to an independent auditor and arbitrator.

\subsection{Cluster stakeholders}

Coupled to the above, the various stakeholders and their responsibilities need to be taken into account too. Sölvell [18] distinguishes the players shown in Figure 13. What is important here is the fact that it takes time to establish a cluster with all the rules and regulations if there are to be so many different stakeholders with different expectations. Again, as with the roles described in the previous paragraph, the responsibilities of each stakeholder, and interest within the cluster, need to be defined and agreed on.

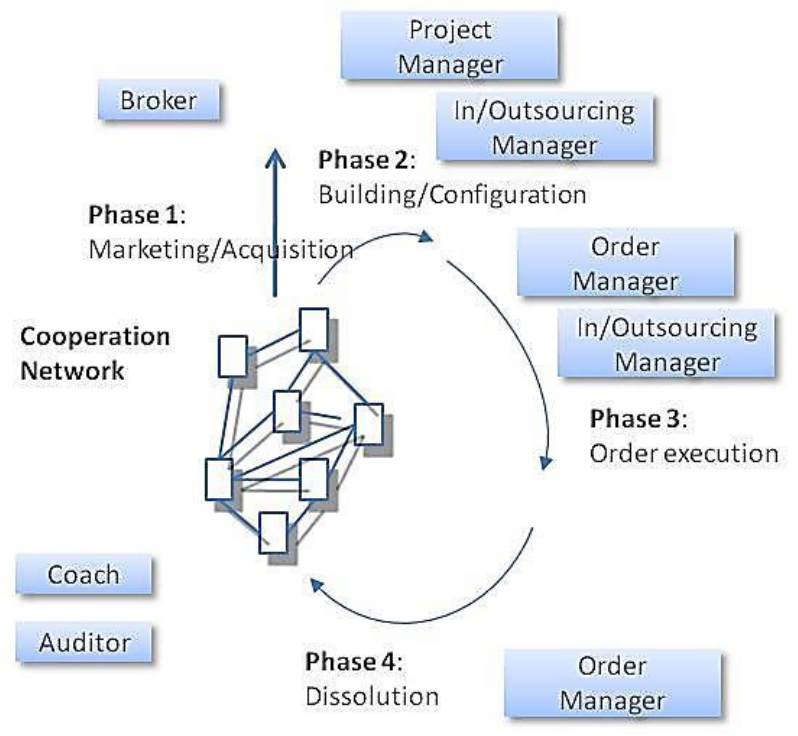

Figure 12: A cluster life cycle (based on 19])

\subsection{Cluster maturity}

Sölvell [18] argues that the development of a cluster normally follows distinct steps, based on a study comparing the successes and failures of different cluster programmes.

First, emerging clusters have to combine factor advantages (such as ore, coal, or wood deposits, traffic infrastructure, climate, etc.) with early entrepreneurship to create the possibility of a successful cluster. If the entrepreneur (one or a few people) is prosperous, the cluster will grow, and other companies will join to support this initial entrepreneur (called a 'hero' in Figure 14). Strong regional demand for industries or even other clusters with synergistic effects will help to enable successful clusters. But success ultimately depends on several ingredients such as demand in general, factor upgrading and specialisation, emerging strategies of competition and cooperation, institutional conditions favouring innovation and change, and political actions.

For the growth of the cluster, it is essential that networking between the different firms takes place and that social capital emerges. The attractiveness of a region increases through competition and cooperation between these firms. If these regional factor advantages are not present, there might be another option that helps to establish successful clusters, such as where university research has been at its core - for example, in Silicon Valley, San Diego, and Cambridge, Massachusetts). 


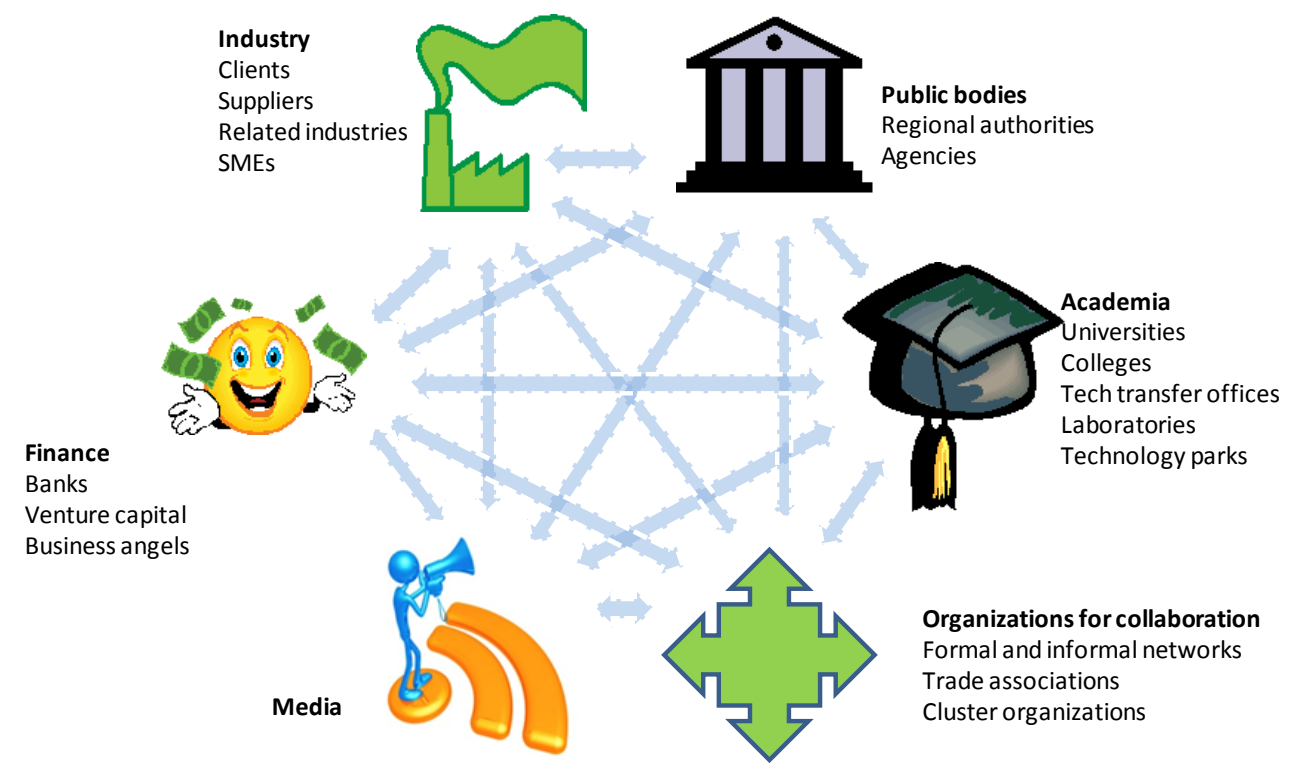

Figure 13: Actors on the cluster stage (adapted from [18])

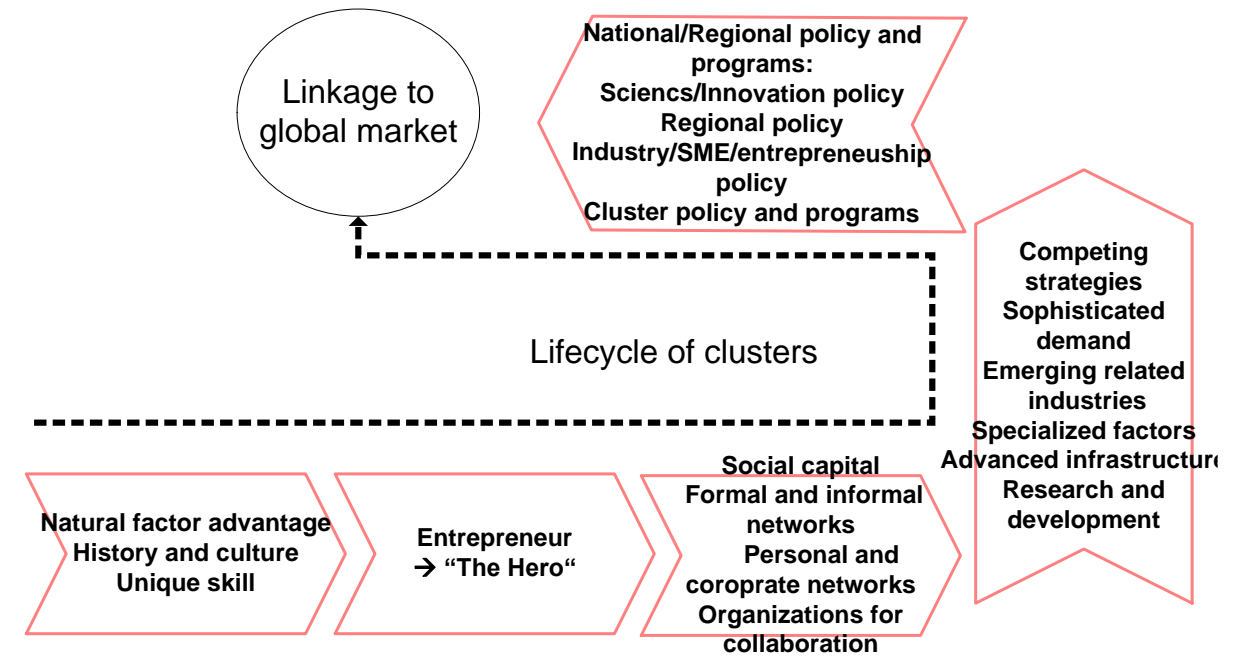

Figure 14: Cluster maturity (adapted from [4])

Next, the general policies within a region have to be established, including the general framework within a region to satisfy the needs of the employees (housing, transportation, culture, etc.) and the companies (land, investment, attraction packages, skilled people, etc.).

Ultimately the linkage to global markets is critical to ensure that the cluster is given the chance for further growth. Raw materials, general goods, and especially knowledge and technology are needed.

It is seen as important that the above steps are followed to ensure a successful cluster; but it is the authors' opinion that it takes a long time to establish - and the tooling cluster initiative in SA does not have the luxury of time on its side. 
Although global cluster initiatives are on the rise, with many examples of successful clusters having been established, a definitive framework or recipe for success is not available. As discussed in this paper, cluster development and success depend on the sound development of an achievable objective for a specific industry, a defined geographical area, or a strategically important activity identified and supported by government. Research suggests that successful clusters have developed over time, with the establishment of trust between the various participants being hugely important.

In South Africa, the tooling industry has been identified as vital in supporting the automotive and packaging industries in particular. Government and Industry bodies have been trying to establish a 'clustering initiative' for a number of years, but so far with limited success.

From this research, the most important steps forward can be summarised as follows:

- Taking into account specifically the low competitiveness of the South African TDM industry, intervention by government is vital if a viable cluster is to be quickly established. A policy framework needs to be based on both fiscal policies and regulatory changes, with financial incentives to entice individual tool rooms to participate.

- $\quad$ Based on the complete order delivery process and possible stakeholders, the specific roles and responsibilities of each participant need to be clearly identified, and individuals need to be assigned to establish a network.

- Most importantly, a detailed marketing strategy needs to be developed, along with operational guidelines for the cluster.

To kick-start this, it is proposed that a pilot project be implemented immediately. To show what can be achieved with cooperation, it is imperative to demonstrate quickly the possible results and advantages of cooperation. Support needs to be given to an initiative in a specific region where cooperation is achieved through sub-contracting. A relatively large company should take responsibility for accepting an order, and then in a supported way use other companies as sub-contractors to complete the order. Although this is not the same as clustering, it can illustrate the possibilities, and - more importantly - it can be implemented almost immediately. If successful, a more formalised structure within a cluster initiative can be developed.

\section{REFERENCES}

[1] Frick, L. 2006. Erfolgreiche Geschäftsmodelle im Werkzeugbau. PhD dissertation. Aachen: RWTH Aachen.

[2] Garms, F. 2012. Diplomarbeit Werkzeugbau Südafrika - Wettbewerbsfähigkeit im internationalen Vergleich, Aachen: RWTH Aachen.

[3] Blueprint. 2005. Final report tool and die industry assessment. Prepared for the counterpart group, South Africa.

[4] Boltz, M., Brings, S., Funke, M. \& Riethausen, M. 2009. Studienarbeit: Clustering concepts: Theoretical background and implementation framework. Stellenbosch: Stellenbosch University.

[5] Von Leipzig, K.H. 2010. Clustering in the South African tooling industry, Proceedings of the International Conference on Competitive Manufacturing, COMA'10, Stellenbosch.

[6] Bilsing, A. \& Klocke, F. 2004. Technological benchmarking in tool and die industry. Proceedings of the International Conference on Competitive Manufacturing, COMA'04, Stellenbosch.

[7] Schleyer, C.C. 2006. Erfolgreiches Kooperationsmanagement im Werkzeugbau. PhD Dissertation. Aachen: RWTH Aachen.

[8] Malherbe, D. 2007. Benchmarking in the South African tool and die manufacturing industry. MScEng dissertation. Stellenbosch: Stellenbosch University.

[9] Kuhlmann, K. 2012. Research and education - comparative or complementary? Approach to competence development for tool and die. Feedback presentation, Pretoria.

[10] Malone, T.W. \& Rockart, J.F. 1991. Computers, networks, and the corporation, Scientific American, Inc, MIT. 
[11] Sum, C., Kow, L.S. \& Chen, C. 2004. A taxonomy of operations strategies of high performing small and medium enterprises in Singapore. International Journal of Operations and Production Management, 24(3/4), 321-345.

[12] Business Day, "South Africa: Mphalwa offers help to small businesses off beaten track", June 27, 2006.

[13] SME survey. 2008. http://www.worldwideworx.com/, accessed Oct 2008.

[14] Boyer, K.K. \& Lewis, M.W. 2002. Competitive priorities: Investigating the need for trade-offs in operations strategy. Production and Operations Management, Volume 11, 9-20.

[15] Bozarth, C. \& McDermott, C. 1998. Configurations in manufacturing strategy: A review and directions for future research, Journal of Operations Management, 16(4), 427-39.

[16] Hayes, R., Pisano, G., Upton, D. \& Wheelwright, S. 2005. Operations, strategy, and technology - pursuing the competitive edge, USA: John Wiley \& Sons.

[17] Lee, K.S., Lim, G.H. and Tan, S.J. 1999. Dealing with resource disadvantage: Generic strategies for SMEs, Small Business Economics, 12, 299-311.

[18] Sölvell, Ö. 2008. Clusters - Balancing evolutionary and constructive forces, Stockholm: Redbook.

[19] Schuh, G., Friedli, T. \& Kurr, M.A. 2005. Kooperationsmanagement, Carl Hanser Verlag, München.

[20] Dyer, J.H., Kale, P. \& Singh, H. 2001. How to make strategic alliances work. MIT Sloan Management Review, Summer, 37-43.

[21] Millarg, K. 1998. Virtuelle Fabrik - Gestaltungsansätze für eine neue Organisationsform in der produzierenden Industrie. PhD Dissertation. Regensburg: Transfer Verlag.

[22] Rosenfeld, S.A. 2002. Creating smart systems: A guide to cluster strategies in less favoured regions, European Union-Regional Innovation Strategies, Carrboro, North Carolina.

[23] Cleveland, J. 2003. Tooling industries facing fundamental restructuring, in: ManufactLINE, Winter, 1-3.

[24] Eversheim, W., Klocke, F., Schuh, G., Baurnhansl, T., Deckert, C., Kampker, A. \& Knodt, A. 2002. Orientierung für den Werkzeug- und Formenbau - Mit Benchmarking von den Besten lernen, Aachener Werkzeug- und Formenbau, 2002. 